\title{
Employers' Recruitment Behaviour: An Empirical Analysis of the Role of Personnel Management Attitudes*
}

\section{Giovanni Russo - Cees Gorter - Peter Nijkamp - Piet Rietveld}

\begin{abstract}
The practical importance of recruitment is witnessed by the existence of specific personnel management functions within firms. The aim of the paper is to investigate the importance of firms' personnel management attitudes for recruitment procedures. We focus on the choice of the first search channel and on the subsequent search spell. The model is empirically estimated by using a data set on recruitment behaviour of $D$ utch firms. The results show that personnel management considerations are important for the choice of the recruitment channel. It appears that advertisement is preferred to the informal channel in that employers believe it is faster and generates applicants who better comply with the hiring standards. Furthermore, employers turn out to prefer mainly the informal channel when recruitment costs are considered important.
\end{abstract}

\section{Introduction}

E conomic theory assumes traditionally that employers are always able to assemble a reliable and efficient work force in order to be competitive in the product market.

Giovanni Russo, $\dagger$ Cees Gorter, Peter Nijkamp, Piet R ietveld, $\dagger$ Department of R egional E conomics, Free U niversity, de Boelelaan 1105, $1081 \mathrm{HV}$ A msterdam, The $\mathrm{N}$ etherlands

* The research has been sponsored by the E conomic R esearch Foundation (ESR), which is part of the Netherlands Organization for Scientific R esearch (NWO). The paper has benefited from constructive comments by an anonymous referee and Jos $\mathrm{V}$ an $\mathrm{O}$ mmeren. The authors are indebted to Intomart b.v. (H ilversum) for providing the data set on recruitment behaviour of Dutch firms.

$\dagger$ A ffiliated to the Tinbergen Institute.

R eceived on M arch 8, 1995 and approved by the E ditorial Board on J uly 10, 1997. 
In practice, firms can modify the composition of their workforce through recruitment. Rynes (1990) defines recruitment as follows: "R ecruitment encompasses all organizational practices and decisions that affect either the number, or types, of individuals who are willing to apply for, or to accept, a given vacancy"' (p. 249). The importance of this recruitment function is clear when one realizes that by hiring the most competent applicants the firm's performances can be significantly enhanced.

Rynes et al. (1980) found that recruiters strategies, recruitment timing and other aspects of the job search process have substantial effects on the allocation of applicants to vacancies. A rvey et al. (1975) reported that delays between recruitment phases had substantial effects on the size and composition of the pool of applicants. Therefore, professional and efficient recruitment will not only shorten vacancy duration, but also improve the quality of the applicants hired.

Despite the potentially important effect that firms' recruitment behaviour is likely to have on the distribution of job opportunities in the economic system (and therefore also on the distribution of unemployment among different types of job seekers), still little empirical analysis of employers' recruitment behaviour is available (an exception being Holzer, 1987, and Barron et al., 1985, in which the authors analyse employers' search time and how the recruitment procedures affect the flow of applicants and employer profits; on this latter issue see also Montgomery, 1991). The part of firms' search strategy to be analysed in the present paper regards the choice of the appropriate search channel(s). Basically one may distinguish between two broad categories: formal and informal search methods. Among the formal methods of search one may include the posting of help wanted advertisements, the use of employment agencies, school recruitment, private employment firms (head hunters). Informal methods rely on the social networks of job seekers such as friends or relatives (Holzer, 1988), and usually provide good quality applicants (K irnan et al., 1989). R oper (1988) in an analysis of the British labour market found that informal search methods are the fastest in filling vacancies, while advertisement is the slowest (with advertisements in a national newspaper being slower than advertisements in a local newspaper). The same results have been found in V an O urs (1989) for the D utch labour market. G orter et al. (1993) found a negative stigma attached to applicants originating through public employment agencies (labour exchange offices) but nevertheless this channel seems to be 
quite effective in order to fill vacancies requiring low skilled workers (Lindeboom et al., 1994). V an Ours and Ridder (1992) point out that employers generally select from a pool of applicants. Gorter and Van Ommeren (1996) identify the use of two main search methods: either to use advertisement first and then add a second search method just before the end of the application period or to begin with an informal method and switch to an alternative method should the informal method fail to provide a suitable candidate in a short time. Consequently, in the present paper we focus on the main factors that determine the choice of the search channel and the duration of search via the chosen channel, with particular attention to the effects of different personnel management attitudes during recruitment. The paper has the following structure. Section 2 introduces the role of personnel management in recruitment. Section 3 introduces the statistical model for the choice of the first search channel. Section 4 describes the data and Section 5 presents the duration model. Section 6 contains the empirical results and Section 7 offers concluding comments.

\section{A personnel management perspective}

Personnel management aims to integrate workers into the firm's production organization, keeping in mind the human nature of employees, their specific characteristics and the firm's environment. $O$ ne of the tasks to be performed by the personnel manager is the recruitment of new employees; to this end, information and communication are of foremost importance. Three types of communication play a role during recruitment procedure: internal communication, external communication and two-way communication.

\subsection{Internal communication (job analysis)}

A $n$ important part of job analysis is the job description. The job description should tell the applicant about the existence and contents of the job, and the contribution to the organization the job holder will be accounted for. M oreover, it should give the employer a measure (or indication) of the productivity the applicant should possess in order to meet the job demands. In order to have a clear picture of the skills a certain position or job requires the following information appears in general to be useful: Job identification: job 
title, department, division, company name, location; Relationships with others: vertical relationships (supervision and monitoring), or horizontal relationships (liaison with others, co-operation); Job content: actual tasks of the job, level of responsibility of the task, frequencies of performance, importance of the task; Working conditions: physical environment (noise, heat), social environment (working in a group, night shift), economic environment (salary, fringe benefits); Performance standards/objectives: expressed in quantitative terms (level of output or sales, time limits to be met) or in qualitative terms (maintaining a certain quality standard within the group); Human requirements: physical and psychological characteristics of the applicant. The stress actual personnel management put on this point supports the view that the information conveyed by the wage alone is only a small part of the information job-seekers use in order to make their employment decision.

\subsection{External communication (the use of recruitment channels)}

A fter the gathering of all relevant information inside the firm, the substance of the information must be made available to job seekers; this is made possible by the use of recruitment channels. Recruitment channels can be classified on the basis of the labour market segmentation in internal and external. Internal channels rely basically on the so called Internal Labour M arket (ILM) which can be defined as an administrative unit within which the pricing and the allocation of labour is governed by a set of administrative rules and procedures (Doeringer and Piore, 1971; Creedy and Whitfield, 1988). The internal labour market can be distinguished from external labour markets, where the pricing, allocation and human capital investments decisions are ruled by economic variables. A n ILM has a strong regional component due to the area's social stability it needs in order to develop. It refers to both a recruitment method and the relationship between a firm and its community. The creation of an ILM depends on the firm's production philosophy; usually IL M s are created to develop long-term relationships to bind workers to the firm (e.g. in order to reduce turnover costs or to fully capture returns from training and other human capital investments, or to prevent other competitors from settling in the same area). By introducing an ILM the market drifts away from perfect competition, salaries and careers within the firm are now driven 
mainly by administrative rules. Depending on the firm's internal organization, entry gates are either located only at the lowest level of the hierarchical structure (thus when someone retires or quits, a vacancy chain is started and the higher positions are filled via the internal channels and the lowest position is filled via the external labour market) or are widespread along the organizational pyramid.

Different sectors of the economy use different manpower strategies in relation to the openness or permeability of the internal/ external labour market (Nielsen, 1993). In fact, sectors with highly seasonal components (that is, high turnover rate, such as the construction sector, for instance) will use the external labour market much more than stable sectors where the high amount of on-the-job training (human capital investments) would suggest binding the labour force more strictly to the firm to avoid human capital losses. The type of recruitment strategy a firm will adopt depends on the opportunities and constraints it faces; in the case of the internal labour market two important factors are noteworthy: (i) the employer's relative power in the labour market; (ii) the question whether the local labour market can supply the skills needed. The preference employers attach to internal sources stems from the extensive pre-screening these candidates undergo before showing up. Applicants referred by employees are pre-screened by the employees themselves.

While informal sources provide a greater percentage of quality applicants, it may be susceptible to inquiries about discrimination against protected groups and minorities. In any case, it is evident that by using only internal channels large parts of the productive working population are precluded from the access to job-related information. A ccording to K irnan et al. (1989), two major theories may explain the fact that informal/internal sources provide better employees: (1) the pre-screening hypothesis and (2) the realistic job information hypothesis. The first theory claims that applicants using this channel have been pre-screened by the referent (usually a current employee) who has the advantage of knowing both the job demands and the applicant's attitudes; thus he is able to judge whether the applicant is suitable for the job, and he will refer only those applicants who are in his opinion suitable for the job concerned. Moreover, current employees perceive that their reputation is at stake with a referral, so that they are encouraged to refer only the best applicants.

The realistic job information hypothesis states that individuals who are provided with realistic job information are more likely to 
stay on the job because their expectations are more likely to be met. In this way the risk of future dissatisfaction is reduced.

\subsection{Two-way communication (selection)}

Selection has become more and more important for firms, since reduced job mobility means that selection errors are likely to stay within the organization longer. Selection can be seen as a two-way process; the stages of the selection process affect both parties' behaviour. In fact, while it is true that the applicants' answers will affect the interviewer's decision whether or not to hire them, it is also true that recruiters' behaviour will affect applicants' decisions whether or not to seek employment in the same organization. Throughout the selection process applicants choose between firms by evaluating the on-going relationship between them and their possible future employer. Selection is the last phase of the recruitment activity and it is intimately connected with the initial job analysis. Selection criteria can be subdivided into two broad categories: organizational and individual job criteria. The first class, organizational criteria, refers to those attributes that may be valuable for the candidate's success within the firm. For example, if the firm is expanding, it may require particularly flexible and adaptable employees. These criteria are seldom made explicit and are often used in an intuitive way. The second group, individual job criteria, refers to those attributes that may guarantee a satisfactory applicant's performance on that job: the hiring standards. A number of factors affect the choice of the most effective selection technique; among those: costs, accuracy, time, type of job, ability of the staff, or economies of scale.

$\mathrm{N}$ eedless to say, the cheapest way to select personnel seems to be the applicants' self-selection. In order to fully exploit this feature, realistic job-related information must be provided to applicants. It may be important to note that self-selection can be triggered by two factors: either by a realistic job-preview or by a seemingly non-professional recruitment procedure (for instance, a long waiting period between successive steps, or delays in replying to candidates). The first factor tends to screen out from the pool all potential applicants who are not suitable for the job, thus enhancing the quality of applicants; the second has the effect of eliminating good applicants who, in the meantime, have found a suitable job elsewhere or who perceive poor professionalism in the firm, thus 
lowering the average quality of the applicants. Moreover, since the job choice is made under imperfect information, recruitment procedures convey signals about unobservable firm's characteristics (such as professionalism).

\section{A statistical model for the choice of the search channel}

Within a framework of profit maximization, the firm chooses its recruitment method on the basis of a comparison of expected costs and expected benefits. Following Gorter et al., (1996), recruitment costs are influenced by the conditions on the labour market, by the firm's attitude towards recruitment and by the conditions on the firm's product market. Expected benefits basically depend on the quality of the candidates (ability) reached by the activated search channel and on the degree of compatibility between the hired applicant and the internal organization of the firm.

The firm chooses its hiring strategy (a reservation value of productivity $\eta$, Fallick, 1992) and it selects among the possible search strategies the one which gives the highest return from the search activity. Reservation productivity serves as a stopping rule, employers will hire any applicant with higher productivity. The net benefit $(U)$ associated to the use of a certain search channel is affected by the characteristics of the vacant position (see Gorter et al., 1996). In our specific case we do not observe this value directly, but we do observe which search channel employers actually choose; moreover, we assume that $\mathrm{U}=\mathrm{U}(\mathrm{z})$ where $\mathrm{z}$ is a vector of vacancy characteristics.

When we use a stochastic model the net benefit associated with the recruitment channel $h$ consists of a systematic component (a function of the observable characteristics) plus a random disturbance that reflects unobserved characteristics in the following manner: $U_{h}(z)=U_{h}(z)+\varepsilon_{h}$ where $\varepsilon_{h}$ is an error term with a density function $\mathrm{p}\left(\varepsilon_{\mathrm{h}}\right)$. Employers will choose the search method yielding the highest net benefit $(h)$, hence $U_{h}=M a x_{m} U_{h}$; given $U_{h}$ and a feasible set of alternative search channels $(m)$, utility maximization implies that:

$$
\mathrm{p}(\text { channel chosen }=\mathrm{h})=\mathrm{p}\left(\mathrm{U}_{\mathrm{h}}>\mathrm{U}_{\mathrm{i}}\right) \forall \mathrm{i} \neq \mathrm{h} \in \mathrm{m}
$$

and if the disturbances $(\varepsilon)$ are independent and identically distributed according to a type I extreme value distribution, we obtain the multinomial logit model (Cramer, 1991). The probability 
that the recruitment channel $h$ is activated (conditional on the vector of observed characteristics z) can be expressed in the following way:

$$
\mathrm{p}(\text { channel chosen }=\mathrm{h} / \mathrm{z})=\frac{\exp \left(U_{\mathrm{h}}\right)}{\sum_{\mathrm{i} \in \mathrm{m}} \exp \left(U_{\mathrm{i}}\right)}
$$

The logit model has the property that the ratio between the probabilities of any two states depends only on the characteristics of the two states and not on those of the other states. This means that the probability that a particular search channel is chosen depends only on the features of the search channels concerned and not on those of the other search channels available; this seems a plausible assumption when different search channels reach disjointed segments of the population with different characteristics. ${ }^{1}$

The choice of the recruitment channel influences the probability of filling the vacancy through the probability of receiving an applicant ${ }^{2}$ and the probability of the applicant being acceptable. Consequently, the success rate of finding a suitable candidate for the vacant position when searching via the optimal search method $h\left(\theta_{h}\right)^{3}$ can be further decomposed into the rate of arrival of applicants (under search strategy $h, \delta_{\mathrm{h}}$ ) and the probability of the applicant being suitable $\left(1-F_{h}\left(\eta_{h}\right)\right)$ where $F$ is the distribution of abilities (or productivity) in the population reached by the search channel $h$. Hence $\theta_{\mathrm{h}}(\mathrm{t})=\delta_{\mathrm{h}}(\mathrm{t})\left[1-\mathrm{F}_{\mathrm{h}}\left(\eta_{\mathrm{h}}\right)\right]$.

The number and average quality of applicants received depend on the firm's search strategy and on the characteristics of labour supply. The latter, however, will not be included in a partial demand-side approach based on vacancy data.

\section{The data set}

The data set used in our empirical work concerns micro data on vacancies and recruitment methods in the $\mathrm{N}$ etherlands. This data set is the result of a survey on employer's search behaviour carried out by I.L.B.O. in 1986; firms were asked about the last vacancy filled in the past six months. The survey inquired about the search channels used and the duration of the recruitment process (defined as the number of weeks elapsed from the beginning of the recruitment process until the hiring of the candidate). Furthermore, other firm 
and vacancy characteristics were also noted. The following recruitment channels were distinguished: informal channels, i.e. internal, personnel referrals, write-in's; advertisement; labour exchange office; others, i.e. temporary placement office, school placements, others. The survey contained complete information on 745 filled vacancies. M oreover, employers were asked about the number of search channels activated, and which of them was the first recruitment channel used. Descriptive statistics on the success probability of different search channels is provided in Table 1 . When advertisement is the first search channel activated in 91 percent of the cases it also becomes the hiring channel; the high effectiveness of this recruitment channel in matching vacancies and job seekers was also found in Lindeboom et al. (1994).

In our sample slightly more than 50 percent of respondents reported the use of only one search channel (the average number of search channels activated is 1.84).

Employers who used more than one search channel were also asked about the opening of the subsequent recruitment channels and on the time elapsed between the opening of the first and what will become the hiring channel. With regard to this last question, 98 percent of the employers who opened more than one search channel reported positive duration between the two openings. This evidence

Table 1. Channels' effectiveness in matching vacancies and job seekers

Hiring channel

\begin{tabular}{lcccccc}
\cline { 2 - 6 } First channel & Informal & Advertisement & L.E.O. & T.P.O. & Others & Total \\
\hline Informal & 190 & 76 & 19 & 4 & 4 & 294 \\
& 64.7 & 25.9 & 6.8 & 1.3 & 1.3 & 39.5 \\
A dvertisement & 17 & 228 & 2 & 2 & 2 & 251 \\
& 6.8 & 90.8 & 0.8 & 0.8 & 0.8 & 33.7 \\
L.E.0. & 16 & 32 & 73 & 7 & 2 & 130 \\
& 12.3 & 24.6 & 56.1 & 5.4 & 1.6 & 17.4 \\
T.P.O. & 1 & 5 & - & 22 & - & 28 \\
& 3.6 & 17.8 & - & 78.6 & - & 3.8 \\
Others & 5 & 6 & 1 & 1 & 29 & 42 \\
& 11.9 & 14.3 & 2.4 & 2.4 & 69.0 & 5.6 \\
Total & 229 & 347 & 96 & 36 & 37 & 745 \\
& 30.7 & 46.6 & 12.9 & 4.8 & 5.0 & 100 \\
\hline
\end{tabular}


Table 2. The choice of the first search channel

\begin{tabular}{lccc}
\hline & Frequency & $\begin{array}{c}\text { Average duration } \\
\text { (in weeks) }\end{array}$ & $\begin{array}{c}\text { Average number } \\
\text { of channels }\end{array}$ \\
\hline First channel activated & & & \\
Informal & 294 & 4.88 & 1.97 \\
A dvertisement & 251 & 6.04 & 1.49 \\
L.E.O. & 130 & 4.99 & 2.13 \\
T.P.O. & 28 & 5.50 & 2.04 \\
Others & 42 & 7.60 & 2.12 \\
Total & 745 & 5.60 & 1.84 \\
\hline
\end{tabular}

strongly suggests a sequential opening of search channels. Since the data set does not completely specify the timing of the openings of all recruitment channels activated, it is not possible to model the recruitment process in a comprehensive and dynamic way. Nevertheless, the choice of the first search channel is of strategic importance, since it will condition the subsequent evolution of the recruitment strategy, as shown in Table 2 (see Gorter and Van O mmeren, 1996). It appears that the choice of advertisement as the first recruitment channel involves longer duration but a lower number of search channels. On the contrary, the activation of the informal channel is usually accompanied by shorter duration but also by a somewhat higher number of auxiliary search channels.

The survey contained also several questions on firms' attitudes towards some aspects of the recruitment process: "recruitment should provide motivated candidates" (motivated) or "recruitment should provide candidates who comply with the hiring standards" (standards) or "recruitment should involve effort" (effort) or "recruitment should provide candidates quickly" (speed) and "recruitment is expensive" (cost). The answer categories were: "Important/not important". These statements resulted in five dichotomous variables under the label "personnel management". Descriptive statistics of the variables used in the empirical application can be found in A ppendix 1.

\section{The duration model}

In our approach to model the duration of search we use a proportional hazard model. The hazard rate $\left(\theta_{\mathrm{h}}\right)$ represents the likelihood to fill a given vacancy between time $t$ and $t+d t$, given that 
the vacancy has lasted until t. In a partial equilibrium analysis, where only the employers' search behaviour is accounted for, it may be considered as a function of an array of vacancy characteristics and the firm's manpower strategies (z). In proportional hazard models the hazard function factorize into two terms: (i) the base line hazard (a function of time); and (ii) a time independent component as a function of the vacancy characteristics (k). To control for the possible existence of unobserved heterogeneity in the observations that would bias the results, we have introduced an error term $v$ that would affect the hazard rate multiplicatively. The hazard rate would then read as follows: $\theta_{\mathrm{h}}(\mathrm{t})=\theta_{\mathrm{h}}(\mathrm{t} \mid v) \mathrm{s}(v)$; where $\mathrm{s}$ is assumed to be a Gamma variate of unit mean and variance $\sigma^{2}$. In this case, we obtain a Gamma mixture of Weibull distributions, which is also known as the Burr distribution (L ancaster, 1992). The survivor function reads as follows:

$$
\bar{G}(t)=\left(1+\sigma^{2} k t^{\alpha}\right)^{-\lambda}
$$

where $k$ is a function of the exogenous time invariant covariates.

The estimation of such a model can be carried out in a straightforward way (by means of maximum likelihood), when only one search channel is used (type A observations). The contribution to the likelihood for these observations is $g(t)$, where $t$ is the duration of the recruitment process, and $\mathrm{g}$ is its probability distribution.

When more than one channel is activated, the estimation will be implemented by right censoring the observation at the moment the additional recruitment channel has been activated. This approach was adopted since by opening another search channel the nature of the search process itself is changed; it becomes a competing risk model and interactions between the competing recruitment channels should be taken into account (E din, 1989). In this second case, we face two types of observations, those for which the opening time of the second channel is known (type B observations) and those for which the opening time of the second channel is not known (type $C$ observations). For type B observations the contribution to the likelihood is the survivor function evaluated at the opening of the second search channel $t_{1}$; i.e. [ $\left.1-G\left(t_{1}\right)\right]$.F or type $C$ observations $t_{1}$ is unknown, but we know that the overall duration of the process is $\mathrm{T}$. Thus, we have to integrate out the censoring time as follows:

$$
\bar{G}\left(t_{1}\right)=\int_{0}^{T} \bar{G}(s) d s
$$


So, the likelihood function for the duration model can be expressed as follows:

$$
L=\prod_{A} g(t) \prod_{B} \bar{G}\left(t_{1}\right) \prod_{C} \bar{G}_{1}(t)
$$

In the model we specify $k$, the function of exogenous covariates ( $z$ ) in equation (3) as follows: $k=\exp \left(z^{\prime} \gamma\right)$ where $\gamma$ are parameters to be estimated, together with $\sigma, \lambda^{4}$ and $\alpha$.

\section{Empirical results}

\subsection{Multinomial logit estimates for the choice of the first search channel}

In the actual estimation we specify $U_{h}(z)$ as a linear function of the vacancy characteristics in the following way: $\mathrm{U}_{\mathrm{h}}(\mathrm{z})=\mathrm{z}^{\prime} \beta_{\mathrm{h}}$ where $\beta_{\mathrm{h}}$ is a vector of parameters to be estimated. The estimates of the multinomial logit model for the choice of the first search channel are given in Table 3.

If the vacant position regards a permanent job then the first search channel activated is most likely to be advertisement. The presence of the personnel department reduces the chance that advertisement is the first search channel used compared to both the informal channel and the residual category. Next, the economic sector variables show that there may exist a special manpower strategy in the construction sector. In this sector there are many seasonal hirings and firings. During the unemployment period workers may remain attached to the firm that, in a subsequent expansion phase may be willing to rehire them (via the informal network or the L.E.O.). Firms in the quaternary sector are more likely to use advertisement. Educational requirements do not seem to play an important role, but the opposite holds true for experience requirements (a finding in agreement with Gorter et al., 1993). The requirement for specific working experience (experience with jobs similar to the one vacant) the most preferred search channel seems to be advertisement, followed by the informal channel, then the labour office and finally the residual channel "others". In case non-specific experience is required, each search channel appears to be preferred to the residual category "others".

Turning to the firm's attitude towards recruitment, it appears that the inclusion of the variables capturing these attitudes, however, 
Table 3. Estimates of the multinomial logit model for the first recruitment channel (standard errors in brackets; * significant at $10 \%$; ** significant at $5 \%$ )

\begin{tabular}{|c|c|c|c|}
\hline \multirow[b]{2}{*}{ Variables } & \multicolumn{3}{|c|}{$\begin{array}{l}\text { First recruitment channel } \\
\text { (Reference channel: informal) }\end{array}$} \\
\hline & $\begin{array}{l}\text { Advertise- } \\
\text { ment }\end{array}$ & $\begin{array}{l}\text { Labour exchange } \\
\text { office }\end{array}$ & Others \\
\hline Constant & $-3.71(0.80)^{*}$ & $-1.15(0.75)$ & $-2.24(1.26)^{*}$ \\
\hline $\begin{array}{l}\text { Personnel management } \\
\text { Effort } \\
\text { M otivated } \\
\text { Speed } \\
\text { Cost } \\
\text { Standards }\end{array}$ & $\begin{array}{c}-0.07(0.23) \\
0.27(0.53) \\
0.67(0.53)^{*} \\
-0.62(0.21)^{* *} \\
0.93(0.48)^{*}\end{array}$ & $\begin{array}{c}0.04(0.26) \\
-0.21(0.52) \\
0.72(0.28) * * \\
-0.39(0.24) \\
-0.21(0.37)\end{array}$ & $\begin{array}{r}-0.31(0.32) \\
1.24(1.07) \\
-0.15(0.31) \\
-0.02(0.30) \\
0.19(0.53)\end{array}$ \\
\hline $\begin{array}{l}\text { Vacancy characteristics } \\
\text { Permanent position } \\
\text { Full-time job }\end{array}$ & $\begin{array}{l}0.83(0.29)^{* *} \\
0.41(0.28)\end{array}$ & $\begin{array}{r}-0.11(0.28) \\
0.44(0.35)\end{array}$ & $\begin{array}{r}-0.03(0.37) \\
0.12(0.40)\end{array}$ \\
\hline $\begin{array}{l}\text { Required education } \\
\text { Extended vocational and high } \\
\text { Secondary } \\
\text { Low vocational }\end{array}$ & $\begin{array}{r}0.34(0.43) \\
0.39(0.38) \\
-0.03(0.37)\end{array}$ & $\begin{array}{l}0.04(0.52) \\
0.00(0.43) \\
0.37(0.37)\end{array}$ & $\begin{array}{l}0.42(0.59) \\
0.01(0.54) \\
0.13(0.49)\end{array}$ \\
\hline $\begin{array}{l}\text { Experience required } \\
\text { Specific } \\
\text { Non-specific } \\
\text { A ge restriction }\end{array}$ & $\begin{array}{l}0.48(0.24)^{* *} \\
0.44(0.33) \\
0.62(0.20)^{* *}\end{array}$ & $\begin{array}{c}-0.58(0.27)^{* *} \\
0.04(0.33) \\
0.25(0.23)\end{array}$ & $\begin{array}{r}-0.38(0.31) \\
-0.94(0.53)^{*} \\
0.16(0.29)\end{array}$ \\
\hline $\begin{array}{l}\text { Firm's characteristics } \\
\text { Personnel department } \\
\text { Large size } \\
\text { M edium size } \\
\text { Industrial sector } \\
\text { Construction sector } \\
\text { Q uaternary sector }\end{array}$ & $\begin{array}{c}-0.41(0.22)^{*} \\
-0.03(0.29) \\
0.64(0.25)^{* *} \\
0.15(0.27) \\
-0.57(0.27)^{*} \\
0.93(0.26)^{* *}\end{array}$ & $\begin{array}{c}-0.03(0.26) \\
-0.61(0.33)^{*} \\
-0.08(0.27) \\
0.48(0.30) \\
0.27(0.31) \\
0.11(0.35)\end{array}$ & $\begin{array}{c}0.39(0.33) \\
-0.56(0.42) \\
-0.07(0.35) \\
0.24(0.34) \\
-0.95(0.45)^{* *} \\
-0.39(0.42)\end{array}$ \\
\hline $\begin{array}{l}-2 \text { Log likelihood restricted model } \\
-2 \text { Log likelihood full model } \\
\text { No. of observations }\end{array}$ & & $\begin{array}{l}1877.87 \\
1702.20 \\
745\end{array}$ & \\
\hline
\end{tabular}

Reference groups of the exogenous variables are given in brackets: required education (primary), size of the firm (small), sector of the firm (services), personnel department (no personnel department), required experience (no experience), age restriction (no age restriction), permanent job (temporary), full-time job (part-time job). 
Table 4. The effect of personnel management variables on the choice of the first search channel (standard errors in brackets; * significant at $10 \%$; - non-significant)

\begin{tabular}{|c|c|c|c|c|c|}
\hline & Speed & M otivation & Standards & E ffort & Cost \\
\hline $\begin{array}{l}\text { A dvertisement vs informal } \\
\text { channel }\end{array}$ & $\begin{array}{l}0.67 \\
(0.23)^{*}\end{array}$ & - & $\begin{array}{l}0.93 \\
(0.48)^{*}\end{array}$ & - & $\begin{array}{l}-0.62 \\
(0.21)^{*}\end{array}$ \\
\hline $\begin{array}{l}\text { A dvertisement vs labour } \\
\text { exchange office }\end{array}$ & - & - & $\begin{array}{l}1.14 \\
(0.52)^{*}\end{array}$ & - & - \\
\hline A dvertisement vs others & $\begin{array}{l}0.82 \\
(0.33)^{*}\end{array}$ & - & - & - & $\begin{array}{l}-0.60 \\
(0.32)^{*}\end{array}$ \\
\hline $\begin{array}{l}\text { Labour exchange office vs } \\
\text { others }\end{array}$ & $\begin{array}{l}0.87 \\
(0.37)^{*}\end{array}$ & - & - & - & - \\
\hline $\begin{array}{l}\text { Labour exchange office vs } \\
\text { informal channel }\end{array}$ & $\begin{array}{l}0.72 \\
(0.28)^{*}\end{array}$ & - & - & - & - \\
\hline O thers vs informal channel & - & - & - & - & - \\
\hline
\end{tabular}

leads to a significant gain in the overall fit of the model. An overview of the significant differences between the search channels due to different personnel management attitudes is presented in Table 4.

E mployers who consider the speed of the recruitment channel in providing a pool of applicants as important, tend to have a higher probability of choosing advertisement or the labour office relative to informal contacts or "others" as first recruitment channel.

Turning now to the costs attitude, it appears that this factor drives the choice away from advertisement. A cross comparison between advertisement and both the residual post others and the informal channel shows that the latter ones are preferred to advertisement when employers consider the cost aspect important.

A comparison of the coefficients within the class regarding the importance of the compliance with the hiring standards, shows a significant dominance of advertisement with respect to the informal channel and the labour exchange office (stigma effect).

Summing up, it may be concluded that advertisement is more likely to be chosen when the speed in generating applicants and the compliance with hiring standards are considered important, a permanent position has to be offered, specific working experience is required, and the firm is medium-sized and operates in the quarternary sector. 


\subsection{Duration model estimates}

The purpose of this section is to shed more light on the influence of personnel management strategies on the duration of search, given the choice of the first search channel. This implies that, even if one uses the same search channel, different attitudes towards recruitment may lead to different durations of the recruitment process. In the actual estimation we adopted the Burr distribution of equation (3); a separate model was estimated for each search channel.

As a first remark, it appears that switching from the exponential specification to the $W$ eibull one gives rise to a significant improvement in the fit of the model. Then, in order to account for the possible presence of heterogeneity, we carried out the estimation of the mixture model, which produces a hazard function displaying an interior maximum. In order to have a first test on the reliability of the model, the estimated empirical hazard rate is plotted against the Kaplan-Meier product limit estimator (non parametric estimator of the hazard rate, see K iefer, 1988).

It should be noticed that in the actual estimation various problems were encountered. In fact, in order to identify the $\alpha$ and $\sigma$ parameters a crucial role is played by the information conveyed by the completed duration spells. If these spells do not display enough statistical variation, the estimation of these two parameters is extremely troublesome (see also e.g. V an Opstal and Theeuwes, 1986). In particular, the number of completed duration spells for the residual channel is as low as 35 (54 for the labour exchange office); moreover the durations are concentrated in the first three or four weeks. Clearly, this is not enough to estimate all parameters of a Burr distribution. The only model that we could implement was an exponential model (a Burr model where the restrictions $\alpha=1$ and $\sigma=0$ are imposed). Next, similar difficulties were encountered during the estimation of the model concerning the labour exchange office, the difference with the residual channel being the number of observations ( 54 completed duration spells, and 76 censored spells). This richer set of observations permits the relaxation of the assumption on the duration dependency parameter, but still the variance of the gamma mixing distribution has to be set to 0 . In other words, we had to estimate a Weibull model (a Burr model where only the restriction $\sigma=0$ is imposed). The estimates of these models and the non-parametrical estimation of the same hazard rate are gathered in A ppendix 2 . 
In fact, the analysis of the censored observations is very telling in itself; the percentage of censored observations is 33 percent for advertisement, 57 percent for the informal channel, 58 percent for the labour exchange office and finally, 50 percent for the residual post. In other words, only one out of three firms using advertisement as the first recruitment channel open an additional search channel, while the figure rises to one out of two (at least) in case firms commence the recruitment process via one of the remaining search channels. This makes one of the advantages of advertisements visible at the aggregated level; i.e. it has a high success probability (see also Table 1 ). ${ }^{5}$

The results of the estimates with the Burr specification referring to the use of advertisement and of the informal channel are given in Table 5.

The first important point concerns the duration dependency of the process. In fact, $\alpha$ appears to be significantly larger than 1 ; that means that there is a positive duration dependence - the longer the state has been occupied the more likely the transition to another state - for these two (main) recruitment channels. This may be due to the fact that a large amount of vacancies are filled after three or four weeks, so that waiting at the beginning of the procedure tends to be worthwhile (or necessary). This phenomenon may be due to the common practice among firms to first gather a pool of applicants and only then to begin the selection procedures. Consequently, during the first few weeks there are hardly any hires and the hazard rate tends to be low. After this initial period selection is carried out and more and more vacancies begin to be filled, it follows that the hazard rate has a steep increase (see V an Ours and Ridder, 1992, and $\mathrm{V}$ an Ours and Ridder, 1993). However, the positive duration dependency goes together with a countervailing effect: the stock of good vacancies (vacancies that are for whatever reason easier to fill) is depleted rather soon at the beginning of the recruitment process; hence after a few weeks only "bad" vacancies (that is vacancies that

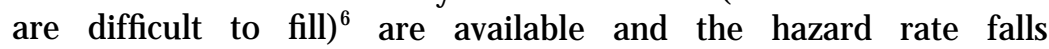
dramatically. Thus we may say that duration dependency is the main drive for transitions at the beginning of the recruitment process, while this drive tend to be overridden by the negative effect due to omitted heterogeneity as the recruitment process lengthens. The shape of the empirical recruitment channel-specific hazard rates (computed at the sample average) for advertisement and the informal channel (plotted against the relative non parametric Kaplan-M eier estimator) is given in Figure 1 and Figure 2, respec- 
Table 5. Duration models estimates, the coefficients give the impact of the independent variables on the hazard rate (standard errors in brackets; * significant at $10 \%$; ** significant at $5 \%$ )

\begin{tabular}{|c|c|c|}
\hline Variables & Informal & Advertisement \\
\hline $\begin{array}{l}\text { Alpha } \\
\text { Constant }\end{array}$ & $\begin{aligned} & 2.41(0.30)^{* *} \\
- & 0.95(0.99)\end{aligned}$ & $\begin{array}{r}2.89(0.37)^{* *} \\
-1.05(1.66)\end{array}$ \\
\hline $\begin{array}{l}\text { Personnel management } \\
\text { E ffort } \\
\text { M otivated } \\
\text { Speed } \\
\text { Cost } \\
\text { Standards }\end{array}$ & $\begin{array}{r}-0.20(0.34) \\
-0.18(0.58) \\
0.57(0.37) \\
0.20(0.34) \\
-0.83(0.54)\end{array}$ & $\begin{array}{r}-0.52(0.33) \\
0.12(0.97) \\
0.41(0.35) \\
0.39(0.34) \\
-0.19(1.05)\end{array}$ \\
\hline $\begin{array}{l}\text { Vacancy characteristics } \\
\text { Permanent position } \\
\text { Full-time job }\end{array}$ & $\begin{array}{c}-0.71(0.42)^{*} \\
0.56(0.49)\end{array}$ & $\begin{array}{l}-0.36(0.53) \\
-0.24(0.43)\end{array}$ \\
\hline $\begin{array}{l}\text { Required education } \\
\text { Extended vocational and high } \\
\text { Secondary } \\
\text { L ow vocational }\end{array}$ & $\begin{array}{l}-1.10(0.60)^{*} \\
-1.44(0.55)^{* *} \\
-0.74(0.55)\end{array}$ & $\begin{array}{l}-3.72(0.92)^{* *} \\
-2.65(0.84)^{* *} \\
-1.65(0.77)^{* *}\end{array}$ \\
\hline $\begin{array}{l}\text { Experience required } \\
\text { Specific } \\
\text { N on-specific } \\
\text { A ge restriction }\end{array}$ & $\begin{array}{l}-0.32(0.38) \\
-0.24(0.50) \\
-0.52(0.33)\end{array}$ & $\begin{array}{r}-0.32(0.41) \\
0.24(0.52) \\
0.22(0.31)\end{array}$ \\
\hline $\begin{array}{l}\text { Firm's characteristics } \\
\text { Personnel department } \\
\text { Large size } \\
\text { M edium size } \\
\text { Industrial sector } \\
\text { Construction sector } \\
\text { Q uaternary sector }\end{array}$ & $\begin{array}{c}0.16(0.34) \\
-0.08(0.44) \\
0.40(0.38) \\
0.11(0.46) \\
0.81(0.37)^{* *} \\
-0.27(0.51)\end{array}$ & $\begin{array}{r}-0.36(0.31) \\
-0.36(0.45) \\
0.03(0.36) \\
-0.47(0.44) \\
0.43(0.53) \\
0.01(0.49)\end{array}$ \\
\hline Sigma & $0.86(0.19) * *$ & $0.92(0.18) * *$ \\
\hline $\begin{array}{l}\text { Log likelihood restricted } \\
\text { No. of observations } \\
\text { Censored observations }\end{array}$ & $\begin{array}{l}-120.72 \\
294 \\
167\end{array}$ & $\begin{array}{c}-336.07 \\
251 \\
83\end{array}$ \\
\hline
\end{tabular}

Reference groups of the exogenous variables are given in brackets: required education (primary), size of the firm (small), sector of the firm (services), personnel department (no personnel department), required experience (no experience), age restriction (no age restriction), permanent job (temporary), full-time job (part-time job). 
Figure 1. Parametric (dashed curve) and non-parametric hazard rate. The informal channel.

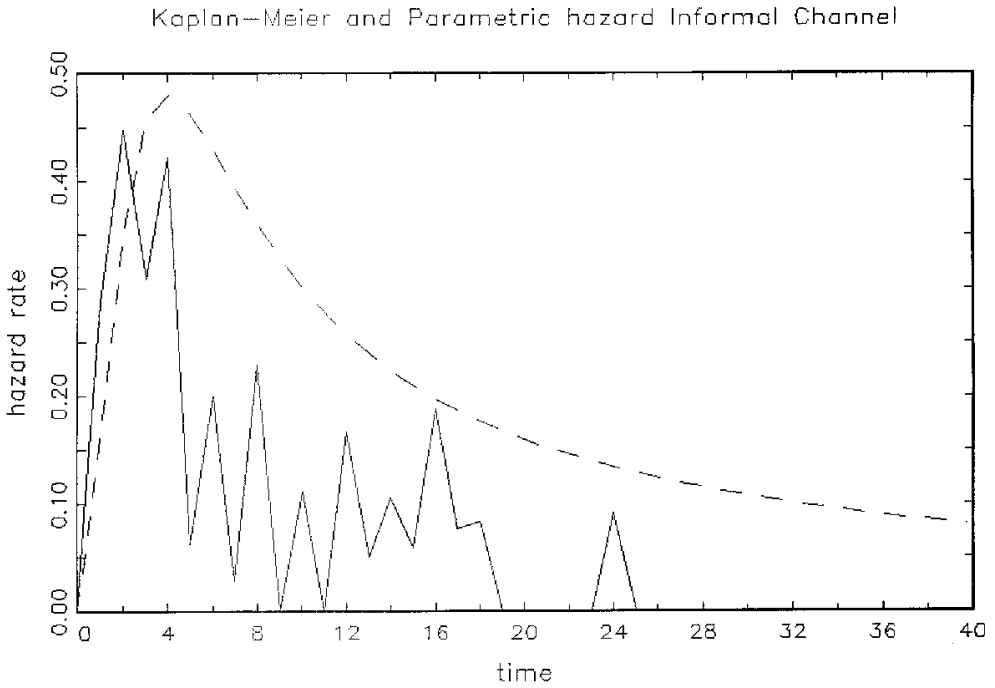

tively. The shapes are remarkably similar; the peak is reached around five or six weeks, the informal channel being somewhat faster.

The second remark concerns educational requirements. The coefficients regarding the different required levels of education are highly significant, with negative signs when advertisement and the informal channel are used as the first search channel (even if the absolute value of the parameters for the two search channels are quite different). As in other studies (for example Gorter et al., 1993), we observe that recruiting for positions requiring higher educational requirement takes longer. The importance of these educational requirements has been stressed - amongst others - by V an O urs and Ridder (1991); in their article the authors found that firms when faced with recruitment problems will rather lower the experience requirements than educational ones. This may explain the negative (and significant) sign (they are more stringent), whereas experience requirements are not significant. In addition, it is likely that the level of education is a signal for the importance of the vacant position for the firm; thus it is plausible that for these more 
Figure 2. Parametric (dashed curve) and non-parametric hazard rate. A dvertisements.

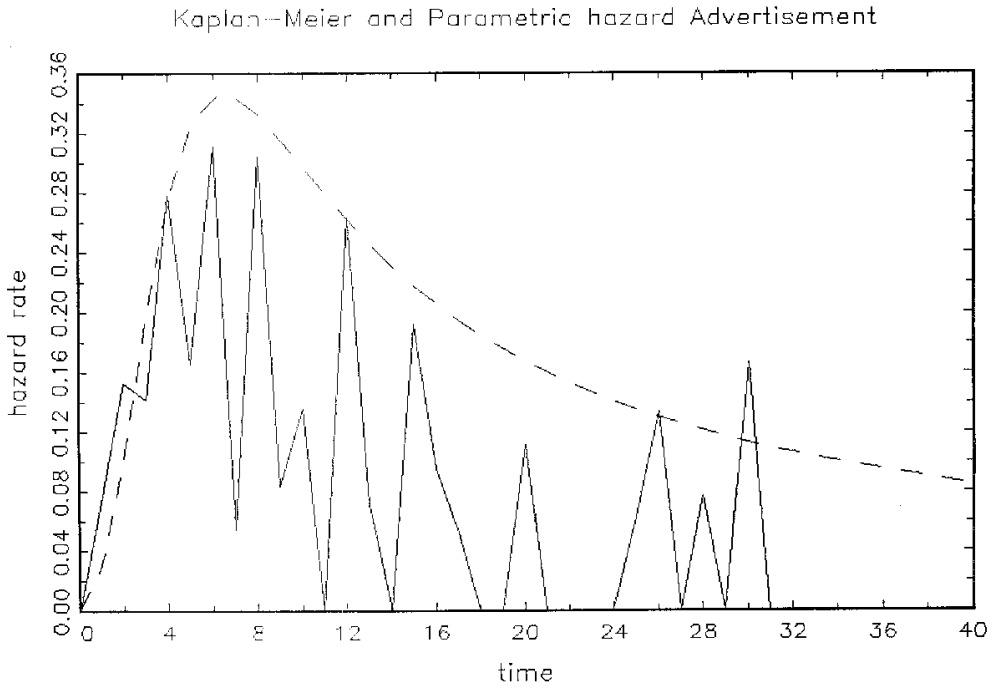

important positions candidates tend to be scarcer; furthermore, a more careful selection is often required. ${ }^{7}$

To continue, the sign of the coefficients for permanent positions is negative (but significant only for the informal channel); thus vacancy duration for permanent positions tends to be longer when employers search informally. Plausibly, firms may be more selective when it is more difficult to adjust possible mistakes made in actual recruitment.

The general conclusion that may be drawn (on the basis of the estimates for the informal channel and advertisement) is that in the first few weeks that "good" vacancies (see note 6) are filled, then longer durations are to be ascribed to unobserved difficulties (as unpleasant working conditions or tasks requiring specific skills, and only few candidates show up). M oreover, ceteris paribus, permanent position with higher educational requirement appears to require more time (and maybe effort) to be filled.

The personnel management variables do not appear to play a significant role in the duration process when advertisement or the informal channel are chosen as the first recruitment channel (the contrary seems to hold when the first search channels activated are 
Figure 3. Non-parametric hazard rate. The labour exchange office.

Kapian-Meier for the Labour Exchange Office

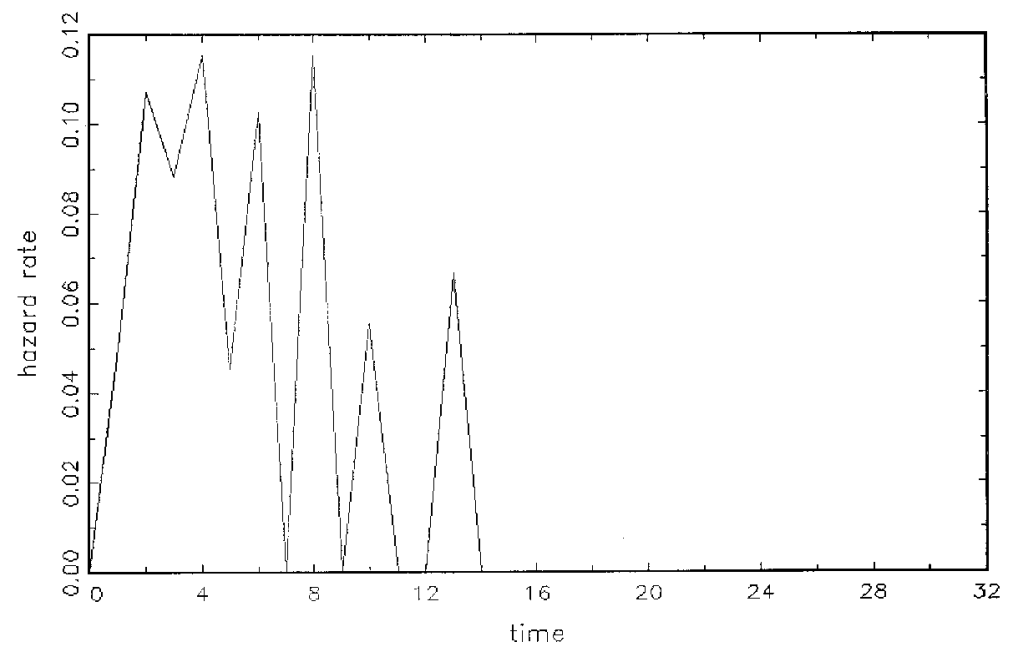

Figure 4. N on-parametric hazard rate. The residual channel 0 thers.

Koplan-Meier for the Residual Channel

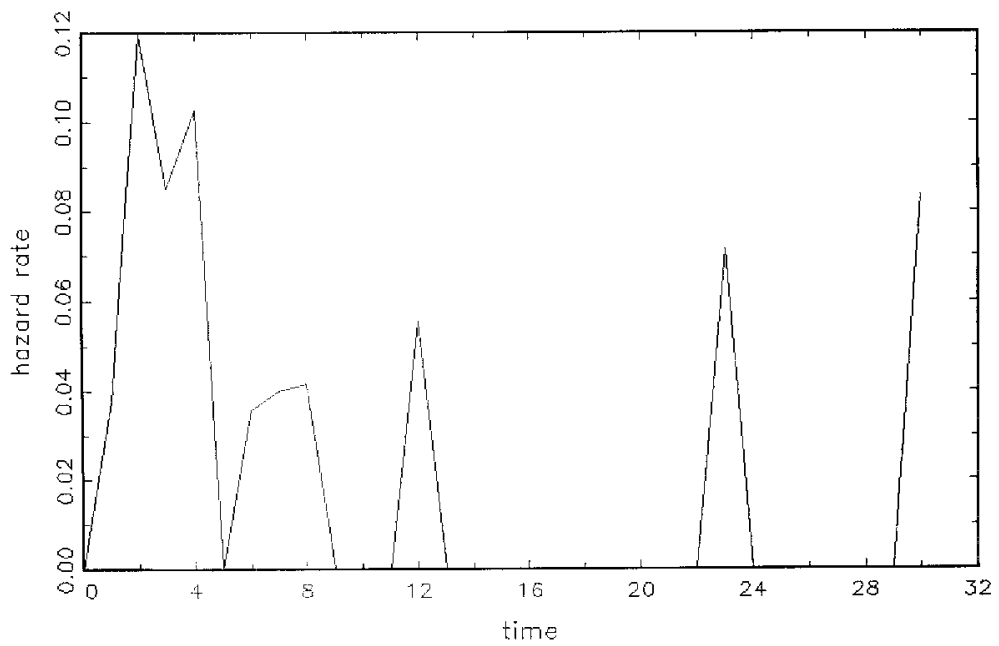

(c) Fondazione Giacomo Brodolini and Blackwell Publishers Ltd 1997. 
the L.E.O. or "others", but the estimate are not robust to changes in the functional form adopted). This phenomenon may be due to the presence of countervailing effects offsetting one another (for example a higher level of search effort may, on the one hand, shorten the search spell but, on the other hand, it may also involve a longer and more careful selection procedure).

\section{Conclusions}

To summarize, employers' personnel management attitudes towards recruitment are important in recruitment, influencing the choice of the first recruitment channel, particularly the choice between the use of advertisement or of the informal search channel. On the other hand, the corresponding duration process is not influenced by these attitudes. Experience requirements and the sector in which the firm operates appear also to be important factors in the choice of the first search channel.

In particular, advertisement appears to be preferred to the informal channel by employers who consider both the speed in providing applicants and the compliance with the hiring standards important factors in recruitment. The informal channel is often preferred to advertisement when employers deem the cost aspect as important.

A s far as the duration of the search spell is concerned, it appears that a key role is played by educational requirements.

At any rate employers' hiring behaviour deserves further attention, possibly with an investigation on how recruitment strategies evolve over the business cycle. 


\section{Appendix 1: The data set}

Mean

Standard deviation

Attitudes towards recruitment

Importance of effort

0.73

0.44

important: 1

Importance of motivation

0.96

0.20

important: 1

Importance of the speed in

0.74

0.44

providing applicants

important: 1

Importance of recruitment costs

important: 1

Importance of compliance with the hiring standards

important: 1

$\mathrm{H}$ iring standards

Extended vocational and university

0.15

0.36

Secondary

Primary vocational

0.31

0.46

Permanent position

0.44

0.50

Full-time position

0.84

0.36

Specific experience required

0.84

0.37

$\mathrm{N}$ on-specific experience required

0.58

0.49

A ge restrictions

0.13

0.34

0.51

0.50

Firm's characteristics

Personnel department

0.45

0.50 present: 1

Firm size (no. employees)

$$
>100 \quad \text { Large: } 1
$$

0.33

0.47

$10<$ size $<100 \quad$ M edium: 1

0.39

0.49

Industrial sector

0.22

0.42

Construction sector

0.21

0.40

Q uaternary sector

0.27

0.44 


\section{Appendix 2: The Labour exchange office and the residual category others}

Table 6. Duration models estimates, the coefficients give the impact of the independent variables on the hazard rate (standard errors in brackets; * significant at $10 \%$; ** significant at $5 \%$ )

\begin{tabular}{|c|c|c|}
\hline Variables & Labour office & Others \\
\hline $\begin{array}{l}\text { A lpha } \\
\text { Constant }\end{array}$ & $\begin{array}{l}1.84(0.11)^{* *} \\
0.96(1.07)\end{array}$ & $\begin{array}{c}1 \\
2.52(2.16)\end{array}$ \\
\hline $\begin{array}{l}\text { Personnel management } \\
\text { E ffort } \\
\text { M otivated } \\
\text { Speed } \\
\text { Cost } \\
\text { Standards }\end{array}$ & $\begin{array}{c}-0.23(0.40) \\
0.42(0.77) \\
-1.02(0.41)^{* *} \\
0.72(0.38)^{*} \\
-1.29(0.51)^{* *}\end{array}$ & $\begin{array}{l}-0.80(0.56) \\
-3.62(1.56)^{* *} \\
1.09(0.51)^{* *} \\
-0.77(0.59) \\
-0.01(0.38)\end{array}$ \\
\hline $\begin{array}{l}\text { Vacancy characteristics } \\
\text { Permanent position } \\
\text { Full-time job }\end{array}$ & $\begin{array}{l}-1.55(0.41)^{* *} \\
-0.59(0.52)\end{array}$ & $\begin{array}{l}-0.03(1.03) \\
-0.40(0.96)\end{array}$ \\
\hline $\begin{array}{l}\text { Required education } \\
\text { Extended vocational and high } \\
\text { Secondary } \\
\text { L ow vocational }\end{array}$ & $\begin{array}{l}-2.35(0.96)^{* *} \\
-0.93(0.76) \\
0.22(0.61)\end{array}$ & $\begin{array}{l}-0.17(0.94) \\
-0.16(0.97) \\
-0.21(0.83)\end{array}$ \\
\hline $\begin{array}{l}\text { Experience required } \\
\text { Specific } \\
\text { Non-specific } \\
\text { A ge restriction }\end{array}$ & $\begin{array}{r}0.55(0.43) \\
-0.01(0.28) \\
0.05(0.32)\end{array}$ & $\begin{array}{l}-0.69(0.52) \\
-0.56(0.93) \\
-0.61(0.41)\end{array}$ \\
\hline $\begin{array}{l}\text { Firm's characteristics } \\
\text { Personnel department } \\
\text { Large size } \\
\text { M edium size } \\
\text { Industrial sector } \\
\text { Construction sector } \\
\text { Q uaternary sector }\end{array}$ & $\begin{array}{l}-0.92(0.46)^{* *} \\
0.87(0.59) \\
-0.18(0.33) \\
-0.25(0.44) \\
-1.25(0.44)^{* *} \\
-1.75(0.61)^{* *}\end{array}$ & $\begin{array}{r}0.31(0.51) \\
-0.38(0.69) \\
-0.16(0.76) \\
0.88(0.52)^{*} \\
0.99(0.75) \\
-0.42(0.69)\end{array}$ \\
\hline Sigma 0 & 0 & \\
\hline $\begin{array}{l}\text { Log likelihood restricted } \\
\text { No. of observations } \\
\text { Censored observations }\end{array}$ & $\begin{array}{l}-89.68 \\
130 \\
76\end{array}$ & $\begin{array}{l}-72.41 \\
70 \\
35\end{array}$ \\
\hline
\end{tabular}

Reference groups of the exogenous variables are given in brackets: required education (primary), size of the firm (small), sector of the firm (services), personnel department (no personnel department), required experience (no experience), age restriction (no age restriction), permanent job (temporary), full-time job (part-time job). 


\section{Notes}

${ }^{1}$ E mployers may activate more search channels for the following reasons: the net benefit associated with the use of a certain search channel may decrease with time since the rate of arrival of applicants declines due to source exhaustion (see also Holzer, 1988). In this case the original (first) search channel may or may not remain open (see G orter and V an O mmeren, 1996). A Iternatively, employers may decide to activate more search channels because they want to reach different types of applicants (with different characteristics) in order to obtain a more composite pool of applicants.

${ }^{2}$ We assume that every candidate applying for the job is willing to accept it.

${ }^{3}$ This is the hazard rate; it represents the chance to fill a vacancy in a small interval $(t+d t)$ given that the position has been vacant until t; see Section 5 .

${ }^{4}$ In the estimation procedure, we imposed for the sake of simplicity, $\lambda=\sigma^{2}$ (see Lancaster, 1992).

${ }^{5}$ The reasons behind the decision to activate additional search channels have been investigated in R usso et al. (1994).

${ }^{6} \mathrm{~N}$ otice that vacancies may be difficult to fill either because they involve unpleasant working conditions, or because the tasks to be performed in the workplace are very demanding and require very specific skills.

${ }^{7}$ Note that similar patterns (though not always significant) are found for the L.E.O.

\section{References}

A rvey R . D ., Gordon M ., M assengill D. and M ussio S. (1975) "D ifferential D ropout $R$ ates of $M$ inority and $M$ ajority J ob Candidates Due to Time Lags Between Selection Procedures", Personnel Psychology 38: 175- 180.

Barron J. M., Bishop J. and Dunkelberg W. C. (1985) "Employer Search: The Interviewing and Hiring of New Employees", The Review of Economics and Statistics 67: 43-52.

Cramer J. S. (1991) The L ogit M odel, London: Edward A rnold.

Creedy J. and Whitfield K. (1988) "The Economic Analysis of Internal Labour M arkets", Bulletin of E conomic Research 40: 247-269.

D oeringer P. and Piore M . J . (1971) Internal L abour Markets and M anpower Analysis, Lexington.

Edin P. A. (1989) "U nemployment Duration and Competing R isks: Evidence from Sweden", Scandinavian Journal of E conomics 91: 639-653.

Fallick B. C. (1992) "Job Security and Job Search in More Than One Labor M arket", E conomic Inquiry 30: 742-745.

Gorter C., Nijkamp P. and Rietveld P. (1993) "The Impact of Employers' Recruitment Behaviour on the Allocation of $V$ acant Jobs to $U$ nemployed J ob Seekers", Empirical E conomics 18: 251-269.

Gorter C., Nijkamp P. and R ietveld P. (1996) "E mployers R ecruitment Behaviour and V acancy Duration an Empirical A nalysis for the Dutch Labour M arket", Applied Economics, forthcoming.

Gorter C. and V an O mmeren J. N. (1996) "Sequencing, Timing and Filling R ates of R ecruitment Channels", Tinbergen Institute D iscussion Paper, TI 96-28/3. 
Holzer H. J. (1987) "Hiring Procedure in the Firm: Their Economic Determinants and O utcomes", NBER Working Paper 2185.

H olzer H . J. (1988) "Search M ethods U se by U nemployed Y outh", Journal of L abor Economics 6: 1-20.

Kiefer N. M. (1988) "Economic Duration Data and Hazard Functions", Journal of E conomic Literature 36: 656-679.

Kirnan J. P., Farley J. A. and Geisinger K. F. (1989) "The Relationship Between Recruiting Source, A pplicant Quality, and $H$ ire Performance: A $n$ A nalysis by Sex, Ethnicity, and A ge", Personnel Psychology 42: 293-308.

Lancaster T. (1992) The Econometric Analysis of Transition Data, Cambridge U niversity Press.

Lindeboom M., Van Ours J. and Renes G. (1994) "Matching Employers and Workers: An Empirical A nalysis of the Effectiveness of Search", Oxford E conomic Papers 46: 45- 67.

M ontgomery J. D. (1991) "Social Networks and Labor-M arket O utcomes: Toward an E conomic A nalysis", American Economic Review 81: 1408- 1417.

Nielsen P. (1993) "Manpower Strategies and Labour M arket Dynamics", Paper Presented at the Workshop on "Duration A nalysis", A arhus: A arhus School of Labour E conomics.

R usso G., Nijkamp P., R ietveld P. and Gorter C. (1994) "A M icroeconomic M odel for Employers' Search in the Labour Market", Tinbergen Institute Discussion Paper, TI 94-156.

Roper S. (1988) "R ecruitment M ethods and V acancy Duration", Scottish Journal of Political Economy 35: 51-64.

R ynes S. L. (1990) "R ecruitment, J ob Choice, and Post Hire Consequences: A Call for N ew Research Directions", in Dunnette M. D. and Hough L. M. (eds.) $\mathrm{H}$ andbook of Industrial and Organizational Psychology, Vol. 2, Palo Alto, California: Consulting Psychology Press.

R ynes S. L., H eneman H. G. III and Schwab D. P. (1980) "Individual Reactions to Organizational Recruiting: A R eview", Personnel Psychology 33: 529-542.

V an Opstal R. and Theeuwes J. (1986) "Duration of U nemployment in the Dutch Labour M arket", De E conomist 134: 351-367.

Van Ours J. (1989) "Durations of Dutch Job Vacancies", De Economist 137: 309-327.

V an O urs J. and Ridder G. (1991) "J ob R equirements and the R ecruitment of $\mathrm{New}$ Employees", E conomics Letters 36: 213-218.

Van Ours J. and Ridder G. (1993) "Vacancy Durations: Search or Selection?", Oxford Bulletin of E conomics and Statistics 55: 187- 198. 